IBIMA Publishing

Advances in Cancer Research \& Treatment

http://www.ibimapublishing.com/journals/ACRT/acrt.html

Vol. 2016 (2016), Article ID 711926, 12 pages

DOI: $10.5171 / 2016.711926$

Research Article

\title{
G-CSF-Producing Renal Cell Carcinoma Characterized by IL-8-Induced Marked Neutrophil Infiltration to Tumor Tissue
}

\author{
Taiichi Kodaka ${ }^{1}$, Emiko Ishikawa Sakane ${ }^{2}$, Hayato Maruoka ${ }^{3}$, Hiroko Tsunemine ${ }^{4}$, \\ Hiroshi Akasaka ${ }^{5}$, Kiminari Ito ${ }^{6}$, Tetsuya Miura ${ }^{7}$, Tomoo Itoh $^{8}$ and Takayuki \\ Takahashi $^{9}$ \\ 1,2,4,5,6,9 Departments of Hematology, Kobe City Medical Center General Hospital, Kobe, Japan \\ ${ }^{3}$ Department of Laboratory Medicine, Kobe City Medical Center General Hospital, Kobe, Japan \\ ${ }^{7}$ Departments of Urology, Shinko Hospital, Kobe, Japan \\ ${ }^{8}$ Department of Diagnostic Pathology, Kobe University Graduate School of Medicine, Kobe, Japan
}

Correspondence should be addressed to: Takayuki Takahashi; takahashi.takayuki@shinkohp.or.jp

Received Date: 12 March 2014; Accepted Date: 31 July 2015; Published Date: 25 May 2016

Academic Editor: Konstantinos G. Stravodimos

Copyright (c) 2016. Taiichi Kodaka, Emiko Ishikawa Sakane, Hayato Maruoka, Hiroko Tsunemine, Hiroshi Akasaka, Kiminari Ito, Tetsuya Miura, Tomoo Itoh and Takayuki Takahashi. Distributed under Creative Commons CC-BY 4.0

\begin{abstract}
Although G-CSF-producing tumor is well-known, co-production of IL-8 by such tumor and IL-8-induced neutrophil chemotaxis to tumor tissue have not been recognized. A 65-year-old male was diagnosed with papillary renal cell carcinoma accompanied by marked intratumoral neutrophil infiltration after left radical nephrectomy. At presentation, laboratory tests showed a white blood cell count of $47.8 \times 10^{9} / \mathrm{l}$ with $84.1 \%$ neutrophils and a high CRP of $18.3 \mathrm{mg} / \mathrm{dl}$. Serum concentrations of G-CSF, IL-6, and IL-8 were elevated to $143 \mathrm{pg} / \mathrm{ml}, 474$ $\mathrm{pg} / \mathrm{ml}$, and 1,260 pg/ml, respectively. After the operation, the white cell count and serum concentrations of these cytokines returned to normal levels. Real-time quantitative PCR of the tumor tissue revealed high gene expressions of G-CSF and IL-8, which appeared to be the cause of the leukocytosis and intratumoral neutrophil infiltration.
\end{abstract}

Keywords: G-CSF, IL-8, renal cell carcinoma, neutrophil infiltration

\section{Introduction}

It had been recognized by clinicians that marked leukocytosis without any evidence of infection occasionally occurs in patients with non-hematologic malignancies. Asano et al first demonstrated the production of human granulopoietic factors by tumor cells from a patient with lung cancer, who was associated with marked leukocytosis, and established the clinical entity of colony-stimulating factor

Cite this Article as: Taiichi Kodaka, Emiko Ishikawa Sakane, Hayato Maruoka, Hiroko Tsunemine, Hiroshi Akasaka, Kiminari Ito, Tetsuya Miura, Tomoo Itoh and Takayuki Takahashi (2016)," G-CSF-Producing Renal Cell Carcinoma Characterized by IL-8-Induced Marked Neutrophil Infiltration to Tumor Tissue ", Advances in Cancer Research \& Treatment, Vol 2016 (2016), Article ID 711926, DOI: 10.5171/2016.711926 
(CSF)-producing tumor, in 1977 (Asano et al. 1977). Thereafter, 3 subtypes of CSF were identified by molecular cloning: granulocyte macrophage colony-stimulating factor (GM-CSF) (Cantrell et al. 1985), granulocyte colony-stimulating factor (G-CSF) (Nagata et al.1986), and macrophage colony-stimulating factor (M-CSF) (Kawasaki et al. 1985). In the first half of the 1990s, Suzuki et al. demonstrated that G-CSF-producing tumors produce not only G-CSF but also interleukin-1 (IL-1) and IL-6, and that IL-1 plays a role as a potent enhancer for the production of G-CSF, IL-6, and IL-1 itself (Suzuki et al. 1991), (Suzuki et al. 1992), (Tsuyuoka et al. 1994). Furthermore, Takahashi et al. showed that G-CSF-producing tumors produce IL-8 in addition to these 3 cytokines, and that such tumors are associated with marked intratumoral neutrophil infiltration, presumably due to IL-8 produced by the tumor itself (Takahashi et al. 2007). In addition, co-production of IL-1, IL-6, and IL8 in G-CSF-producing tumors appears to be caused by hyperactivation of NF-?B because the expression of these 4 cytokine genes is up-regulated by this transcription factor (Takahashi et al. 2007). To our knowledge, however, there have been no reports describing IL-8-induced intratumoral neutrophil infiltration in G-CSF-producing tumors other than ours. Recently, we encountered a patient with renal cell carcinoma that produced G-CSF, IL-6, and IL-8. On pathohistological examination, marked neutrophil infiltration in the tumor tissue of surgically resected kidney was observed. We consider this neutrophil infiltration in the tumor tissue to be pathohistologically important, and thus report the serum cytokine profiles, gene expression of G-CSF and IL-8 by the renal tumor, and the histological picture of the tumor in this patient.

\section{Case Report}

A 65-year-old male was admitted to a hospital because of fever and lumbago. As the past medical history, he had hypertension and hyperlipidemia. His family history was unremarkable. Laboratory tests showed a white blood cell (WBC) count of $53.7 \times 10^{9} / 1$ with $88 \%$ neutrophils, a hemoglobin concentration of $7.7 \mathrm{~g} / \mathrm{dl}$, and a platelet count of $596 \times 10^{9} / \mathrm{l}$. Serum concentration of C-reactive protein (CRP) was elevated to 15.3 $\mathrm{mg} / \mathrm{dl}$ (normally below $0.3 \mathrm{mg}$ ). Computed tomography ( CT ) of the abdomen demonstrated a large mass in the upper pole of the left kidney. Therefore, he was referred to the Departments of Hematology and Urology, Shinko Hospital, Kobe, Japan, and admitted to the latter department in October 2012.

Physically, the patient was $157 \mathrm{~cm}$ and 51.0 $\mathrm{kg}$ in height and weight, respectively, with a body temperature of $37.6^{\circ} \mathrm{C}$. Neither superficial lymphadenopathy nor hepatosplenomegaly was noted. Neurologic examinations were unremarkable. 
Laboratory tests on admission (Table 1) showed a WBC count of $47.8 \times 10^{9} / 1$ with 84.1\% neutrophils, a hemoglobin concentration of $7.7 \mathrm{~g} / \mathrm{dl}$, and a platelet count of $487 \times 10^{9} / \mathrm{l}$. Serum concentrations of alkaline phosphatase (ALP), gamma-glutamyl transpeptidase (?-GTP), lactate dehydrogenase (LDH), and creatinine were elevated to $521 \mathrm{IU} / \mathrm{l}$ (normally 115-360 IU), 73 IU/l (normally 0-30 IU), 251 IU/l (normally 120-230 IU), and $1.08 \mathrm{mg} / \mathrm{dl}$ (normally 0.50-1.00 mg), respectively, while those of L-aspartate aminotransferase (AST) and L-alanine aminotransferase (ALT) were almost within normal limits. The serum concentration of C-reactive protein (CRP) was markedly elevated to $18.3 \mathrm{mg} / \mathrm{dl}$ (normally below $0.3 \mathrm{mg}$ ). Urinalysis and urinary cytodiagnosis revealed no sign of urinary tract infection and class II (no atypia), respectively. Blood and urine cultures resulted in no growth of microorganisms.

Table 1 Laboratory findings on admission (October 2012)

\begin{tabular}{lclrl}
\hline RBC & $2830 \times 10^{9} / \mathrm{L}$ & TP & $7.2 \mathrm{~g} / \mathrm{dL}$ \\
$\mathrm{Hb}$ & $7.7 \mathrm{~g} / \mathrm{dL}$ & ALB & $3.1 \mathrm{~g} / \mathrm{dL}$ \\
$\mathrm{Hct}$ & $24.5 \%$ & $\mathrm{AST}$ & $33 \mathrm{IU} / \mathrm{L}$ \\
$\mathrm{MCV}$ & $86.6 \mathrm{fL}$ & $\mathrm{ALT}$ & $44 \mathrm{IU} / \mathrm{L}$ \\
$\mathrm{PLT}$ & $48.7 \times 10^{9} / \mathrm{L}$ & $\mathrm{ALP}$ & $521 \mathrm{IU} / \mathrm{L}$ \\
WBC & $47.8 \times 10^{9} / \mathrm{L}$ & $\mathrm{V} \mathrm{GTP}$ & $73 \mathrm{IU} / \mathrm{L}$ \\
Neut & $84.1 \%$ & T.BIL & $0.4 \mathrm{mg} / \mathrm{dL}$ \\
Eos & $2.3 \%$ & $\mathrm{LDH}$ & $251 \mathrm{IU} / \mathrm{L}$ \\
Bas & $1.3 \%$ & AMY & $121 \mathrm{IU} / \mathrm{L}$ \\
Mon & $6.0 \%$ & BUN & $15.1 \mathrm{mg} / \mathrm{dL}$ \\
Lym & $6.3 \%$ & $\mathrm{CRTN}$ & $1.08 \mathrm{mg} / \mathrm{dL}$ \\
NAP rate & $100 \%$ & $\mathrm{CRP}$ & $18.3 \mathrm{mg} / \mathrm{dL}$ \\
NAP score & 489 & Ferritin & $960 \mathrm{ng} / \mathrm{mL}$ \\
\hline Abbreviation, NAP: neutrophil alkaline phosphatase.
\end{tabular}

Abbreviation, NAP: neutrophil alkaline phosphatase.

Contrast CT scanning of the chest and abdomen demonstrated a highly necrotic mass with a major axis of $9 \mathrm{~cm}$ arising from the upper pole of the left kidney, which was associated with tumor embolism of the renal vein (Fig. 1A, B). Magnetic resonance imaging (MRI) of the abdomen confirmed the findings of CT scanning and showed direct tumoral invasion to the adrenal gland. These images of the tumor strongly suggested renal cell carcinoma (RCC). CT scanning and MRI also demonstrated no infectious lesion. Bone scintigraphy showed no evidence of bone metastasis. 

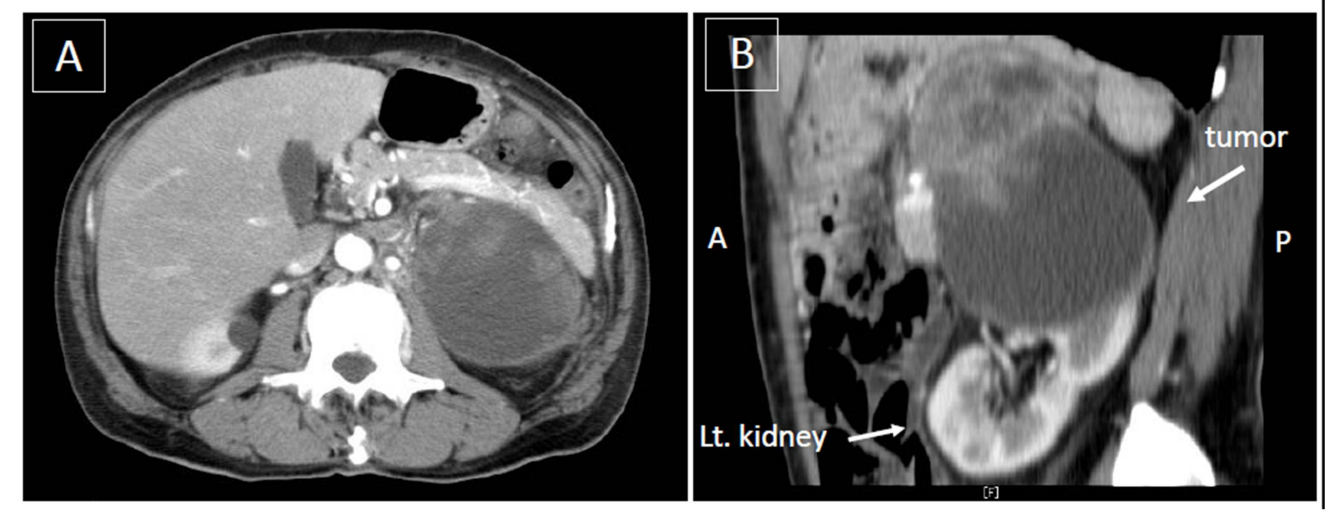

Figure 1: Contrast CT scanning of the abdomen.

A: CT scanning (axial image) at the level of the upper pole of the left kidney shows a heterogeneously enhanced mass with a major axis of $9 \mathrm{~cm}$. The mass is encapsulated with fibrous tissue, resulting in a smooth surface.

B: CT scanning (sagittal image) of the left kidney. The tumor is arising from the upper pole of the left kidney.

Because of the marked leukocytosis, the presence of renal tumor, and no evidence of infection, the renal tumor was highly suspected to be CSF-producing. We thus measured serum concentrations of cytokines by enzyme-linked immunosorbent assay (ELISA). The assay was commercially performed at SRL (Hachioji, Japan). Serum concentrations of G-CSF, IL-6, IL-8, and
TNF-? ?were elevated to $474 \mathrm{pg} / \mathrm{ml}$ (normally less than $39.0 \mathrm{pg}$ ), $143 \mathrm{pg} / \mathrm{ml}$ (normally less than $4.0 \mathrm{pg}$ ), $1,260 \mathrm{pg} / \mathrm{ml}$ (normally less than $2.0 \mathrm{pg}$ ), and $12.5 \mathrm{pg} / \mathrm{ml}$ (normally 0.6 to $2.8 \mathrm{pg}$ ), respectively (Table 2). The high blood levels of G-CSF, IL-6, and TNF- $\alpha$ appeared to have caused the leukocytosis, high CRP, and fever in the present patient 
Table 2 Blood cytokine concentrations before and after nephrectomy

\begin{tabular}{lrcrr}
\multicolumn{2}{c}{$\begin{array}{c}\text { Before } \\
\text { (Nov 2012) }\end{array}$} & & $\begin{array}{c}\text { After } \\
\text { (Jan 2013) }\end{array}$ & Normal range \\
\hline IL-1 $\alpha$ & $<3.9$ & & & \\
IL-6 & 143 & nephrectomy & 4.9 & $<4.0$ \\
IL-8 & 1,260 & $\downarrow$ & 40.9 & $<2.0$ \\
G-CSF & 474 & & 36.1 & $<39.0$ \\
GM-CSF & $<8$ & & & \\
TNF- $\alpha$ & 12.5 & & 2.7 & $0.6 \sim 2.8$ \\
MCP-1 & 133 & & & $200 \sim 722$ \\
\hline
\end{tabular}

All values are in $\mathrm{pg} / \mathrm{mL}$. Abbreviations, IL-1 $\alpha$ : Interleukin-1alpha, G-CSF: granulocytes colony-stimulating factor, GM-CSF: granulocyte macrophage colonystimulating factor, TNF- $\alpha$ : tumor necrosis factor-alpha, MCP-1: monocyte chemoattractant protein-1.

The patient subsequently underwent radical nephrectomy of the left kidney in November 2011. Intraoperatively, the renal tumor was found to have invaded the left adrenal grand and firmly adhered to the pancreas tail; therefore, resection of the left adrenal gland and pancreas tail, and splenectomy were simultaneously performed. Histopathological examination of the resected renal tumor revealed it to be stage pT3a, G3, v1, ly1 with sarcomatoid differentiation papillary RCC (Fig. 2A), and the adrenal gland-invaded tumor showed undifferentiated features of RCC, which was accompanied by marked intratumoral neutrophil infiltration (Fig. 2B, C). Interestingly, neutrophil infiltration was not prominent in the differentiated component (Fig. 2A). After the operation, the patient became afebrile, and the WBC counts and CRP levels returned to normal levels (Fig. 3). Serum concentrations of G-CSF, IL-6, IL-8, and TNF- ? also returned to normal or nearly normal levels (Table 2). Real-time quantitative PCR (RQ-PCR) of the tumor tissue revealed high gene expressions of G-CSF and IL-8 (described in Materials and Methods, and Results). From these findings, a diagnosis of G-CSF-producing RCC was made. 


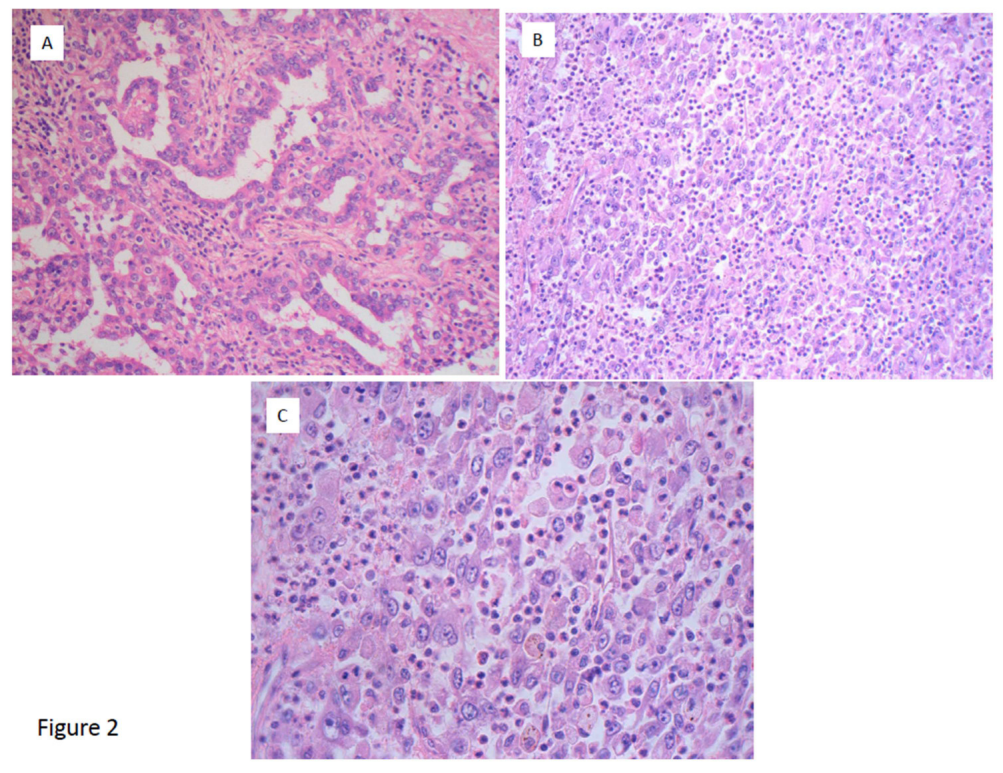

Figure 2: Histological picture of the tumor taken at nephrectomy.

A: The renal tumor tissue shows the features of relatively differentiated papillary RCC.

Neutrophil infiltration is not prominent. H-E staining, $\times 200$.

B: The adrenal gland-invaded tumor shows undifferentiated features of RCC. Marked intratumoral neutrophil infiltration is seen. H-E staining, $\times 200$.

C: Higher magnification $(\times 400)$ of the same tumor (H-E staining).

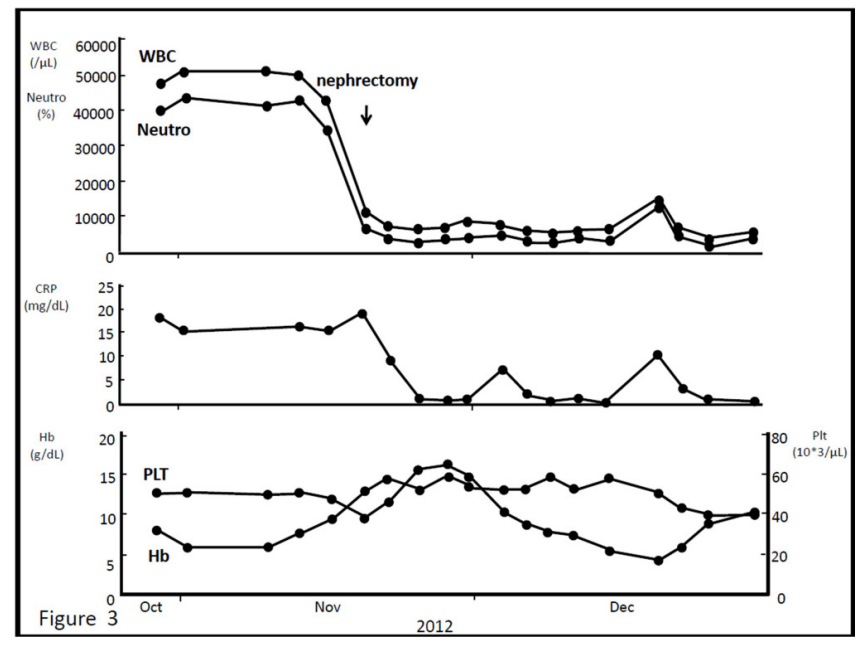

Figure 3: Changes of laboratory data before and after nephrectomy. High WBC/neutrophil counts and high serum CRP levels before the nephrectomy returned to normal levels. 
The patient, however, had to stay in hospital because he developed aspiration pneumonia, adhesive ileus, recurrent esophageal ulcer, and cerebral infarction. In June 2013, serum enzyme levels of the biliary tract and then those of transaminases increased, and he became icteric one month later. He developed cancerous peritonitis and CT scanning showed metastatic lesions in the diaphragm. The WBC count increased to $483 \times 10^{9} / 1$ with 93\% neutrophils, indicating the recurrence of the G-CSF-producing tumor. The patient died at the end of August, 9 months after the operation.

\section{Materials and methods}

Total RNA was extracted from resected tumor tissue and a T-cell tumor cell line, MOLT4, as a negative control, using RNeasy Mini Kit (QIAGEN, Valencia, CA, USA). One microgram of total RNA was reverse-transcribed by SuperScript VILO cDNA Synthesis Kit (Invitrogen, Carlsbad, California, USA). For G-CSF and IL-8 gene, RQ-PCR was performed using Sso Fast EvaGreen Supermix (Bio-Rad, Mississauga, ON, Canada). The ABL gene was chosen as a housekeeping gene to evaluate the amount and amplification of cDNA. The gene-specific primers used were 5'-AAGCTGGTGAGTGAGTGTGC-3' and 5'-ATGGAGTTGGCTCAAGCAGC-3' for G-CSF, 5'-GGTGCAGTTTTGCCAAGGAG-3' and 5'-TTCCTTGGGGTCCAGACAGA-3' for IL-8, 5'-TGGAGATAACACTCTAAGCATAACTAAAGGT3' and 5'-GATGTAGTTGCTTGGGACCCA-3' for ABL. The quantification of each gene expression was performed according to the method by Østergaard et al (Østergaard et al. 2004). To quantify the individual expression levels, we measured quantification cycles (Cq) for these genes, in which the fluorescence intensity of each PCR product reached the same level (Table 3). Then, we calculated the expression levels of each gene per 10,000 copies of $a b l$ gene according to the following formula: $10,000 \times 2^{\wedge}\left(\mathrm{Cq}_{\mathrm{ABL}}-\mathrm{Cq}_{\mathrm{TARGET}}\right)$, assuming PCR amplification efficiency as 2 .

Results

As shown in Table 3, the expression levels of IL-8 and G-CSF were 352,610, and 18,790 times of that of MOLT4, respectively. 


\begin{tabular}{ccc} 
Table 3 & \multicolumn{2}{l}{$\begin{array}{l}\text { IL-8 and G-CSF gene expressions by resected tumor of the present patient } \\
\text { as evaluated by real-time quantitative polymerase chain reaction }\end{array}$} \\
\hline & Patient & MOLT4 \\
\hline $\mathrm{Cq}_{\mathrm{IL}-8}$ & 22.97 & 37.08 \\
$\mathrm{Cq}_{\mathrm{G}-\mathrm{CSF}}$ & 27.20 & 38.48 \\
$\mathrm{Cq}_{a b l}$ & 28.11 & 24.34 \\
& & \\
& Patient & MOLT4 \\
\hline IL-8 (copies/10,000 abl copies) & 35,2610 & 1 \\
$\mathrm{G}-\mathrm{CSF}$ (copies/10,000 ab/ copies) & 1,8790 & 1 \\
\hline
\end{tabular}

$a b /$ gene: A housekeeping gene used as the internal control. MOLT4 : A T cell tumor cell line used as the negative control.

\section{Discussion}

Regarding the diagnosis of G-CSF-producing tumor, the present case fulfills the criteria proposed by Asano et al., that is, marked granulocytosis, elevated serum level of G-CSF, normalization of granulocyte count and serum G-CSF level following tumor resection, and demonstration of G-CSF production by the tumor. As for the organ of origin of the G-CSF-producing tumor, it varies and includes the lung (Asano et al. 1977), (Nakamura et al. 1997), stomach (Tahara 1990), pancreas (Joshita et al. 2009), thyroid (Kang K et al. 2013) (Vassilatou et al. 2006), gingiva (Kobayashi et al 2012), kidney (Wang et al 2006), (Sugiura et al. 2007), (Kanda et al 2011), bladder (Ito et al. 1990), and ovary
(Münstedt et al. 2010).

G-CSF-producing RCC is relatively rare among renal cancers, and being associated with a poor prognosis (Wang et al. 2006). Currently, no standard and effective treatment is available for this type of tumor (Wang et al. 2006). To our knowledge, however, radical nephrectomy and/or combination chemotherapy with gemcitabine and nedaplatin (Sugiura et al 2007), or that with sorafenib and S-1 (Kyono et al. 2011) are potentially effective treatment options.

Regarding IL-8 production by malignant tumors, Takahashi et al. described that there are 2 types: one is IL-8 production in the multi-cytokine production of G-CSF-producing tumors like the present case, 
and the other is sole IL-8 production by tumors (Takahashi et al. 2007), although the degrees of intratumoral neutrophil infiltration are similar in these two types of tumor (Takahashi et al 2007). In terms of the important differences between these 2 types, the latter patients are afebrile and exhibit normal CRP levels and mild leukocytosis, presumably caused by IL-8-activated neutrophil mobilization from the marginal pool, but not enhanced granulopoiesis as in G-CSF-producing tumors (Takahashi et al. 2007), (Terashima et al. 1998).

In relation to neutrophil infiltration in tumor tissue, biliary system- dominant liver dysfunction was observed at presentation and during the recurrence of the tumor in the present patient. Furthermore, the patient developed marked jaundice with direct bilirubin dominance. Drug-induced liver dysfunction was ruled out. Suzuki et al reported liver damage in patients with G-CSF-producing tumor (Suzuki et al. 1993). In the postmortem examination of the liver, neutrophils infiltrated both the portal area and the centrilobular zone even in patients without liver metastasis, and the authors speculated that the G-CSF- and presumably IL-8-activated neutrophils which passively infiltrated the liver and accumulated themselves in the above mentioned areas, caused the liver damage. We speculate on a similar event caused by infiltrated neutrophils in the liver because the pattern of liver dysfunction was biliary system-dominant, as in patients in the study by Suzuki et al (Suzuki et al. 1993).

G-CSF-producing tumors are associated with a poor prognosis. For example, there have been no patients who survived for more than 1 year after diagnosis in G-CSF-producing tumors of the urinary tract (Sugiura et al. 2007), (Kanda et al. 2011), (Ito et al. 1990). Regarding the poor prognosis, Gregory et al. discussed the relationship between tumor growth and neutrophil infiltration and proposed the concept of tumor-associated neutrophils (TAN) (Gregory et al. 2011). Although they discussed TAN in non-CSF-producing tumors, the relationship between tumor growth and neutrophils appears also to occur in G-CSF- and IL-8-producing tumors. In terms of the mechanism by which TAN confer an advantage for tumor growth, they proposed several factors: first, infiltrated neutrophils secrete oncostatin $\mathrm{M}$ that makes tumor cells produce vascular endothelial growth factor or hepatocyte growth factor, which subsequently enhances tumor invasion or growths. Second, neutrophils produce reactive oxygen species that induce tumor transformation through DNA injury and repair. Third, IL-8-activated neutrophils promote tumor metastasis through their adhesion to vascular endothelium and subsequent expression of integrin by endothelial cells, which leads to the adhesion of the tumor cells and extravascular tumor invasion. Fourth, neutrophil elastase destroys insulin receptor substrate, which leads to 
phosphoinositide 3-kinase activation and tumor growth. In relation to TAN, Bellocq et al. and Jansen et al. observed that the presence of intratumoral neutrophils is associated with a poor prognosis in bronchioloalveolar carcinoma and localized RCC, respectively (Bellocq et al. 1998),(Jensen et al. 2009).

In conclusion, physicians should be aware of intratumoral neutrophil infiltration, which is caused by IL- 8 production by the tumor, and biliary system-dominant liver dysfunction, which may be caused by intrahepatic neutrophil infiltration in G-CSF-producing tumors.

\section{References}

1. Asano, S., Urabe, A., Okabe, T., Sato, N., Kondo, Y. (1977) "Demonstration of granulopoietic factor(s) in the plasma of nude mice transplanted with a human lung cancer and in the tumor tissue", Blood, 49 (5) 845-852.

2. Bellocq, A., Antoine, M., Flahault, A., Philippe, C., Crestani, B., Bernaudin, J. F., Mayaud, C., Milleron, B., Baud, L., Cadranel, J. (1998) "Neutrophil alveolitis in bronchioloalveolar carcinoma: induction by tumor-derived interleukin-8 and relation to clinical outcome," The American journal of pathology, 152(1) 83-92.

3. Cantrell, M. A., Anderson, D., Cerretti, D. P., Price, V., McKereghan, K., Tushinski, R. J.,
Mochizuki, D. Y., Larsen, A., Grabstein, K., Gillis, S., Cosman, D.(1985) “Cloning, sequence, and expression of a human granulocyte/macrophage colony-stimulating factor," Proceedings of the National Academy of Sciences of the United States of America, 82 (18) 6250-6254.

4. Gregory, A. D., Houghton, A. M. (2011) "Tumor-associated neutrophils: new targets for cancer therapy," Cancer research, 71(7)2411-2416.

5. Ito, N., Matsuda, T., Kakehi, Y., Takeuchi, E., Takahashi, T., Yoshida, O. (1990) "Bladder cancer producing granulocyte colony-stimulating factor," The New England journal of medicine, 323(24)1709-1710.

6. Jensen, H. K., Donskov, F., Marcussen, N., Nordsmark, M., Lundbeckm, F., von der Maase, H. (2009) "Presence of intratumoral neutrophils is an independent prognostic factor in localized renal cell carcinoma," Journal of clinical oncology, 27(28)4709-4717.

7. Joshita, S., Nakazawa, K., Sugiyama, Y., Kamijo, A., Matsubayashi, K., Miyabayashi, H., Furuta, K., Kitano, K., Kawa, S. (2009) "Granulocyte-colony stimulating factor-producing pancreatic adenosquamous carcinoma showing aggressive clinical course," Internal Medicine, 48 (9) 687-691.

8. Kanda, S., Inoue, T., Tsuruta, H., Chiba, S.,

Taiichi Kodaka, Emiko Ishikawa Sakane, Hayato Maruoka, Hiroko Tsunemine, Hiroshi Akasaka, Kiminari Ito, Tetsuya Miura, Tomoo Itoh and Takayuki Takahashi (2016), Advances in Cancer Research \& Treatment, DOI: $10.5171 / 2016.711926$ 
Obara, T., Saito, M., Kumazawa, T., Tsuchiya, N., Satoh, S., Habuchi, T. (2011) “Granulocyte colony stimulating factor-producing spindle cell renal cell carcinoma successfully treated by chemotherapy consisting of gemcitabine and doxorubicin," Hinyokika Kiyo, 57(7)385-389. (In Japanese with English abstract)

9. Kang, K., Park, J. H., Ryu, J. Y., Lee, S. Y., Ko, G. J., Kwon, Y. J. (2013) “Acute pyelonephritis with anaplastic thyroid carcinoma producing granulocyte colony-stimulating factor," Blood research, 48(1) 63-66.

10. Kawasaki, E. S., Ladner, M. B., Wang, A. M., Van Arsdell, J., Warren, M. K., Coyne, M. Y., Schweickart, V. L., Lee, M. T., Wilson, K. J., Boosman, A., Stanley, E.R., Ralph, P., Mark, D. F.(1985) "Molecular cloning of a complementary DNA encoding human macrophage-specific colony-stimulating factor (CSF-1)," Science, 230 (4723) 291-296.

11. Kobayashi, J., Miyazaki, A., Yamamot, T., Nakamori, K., Suzuki, R., Kaneko, T., Suzuki, N., Hiratsuka, H. (2012) "Granulocyte colony-stimulating factor-producing squamous cell carcinoma of the lower gingiva: a case report," Head \& neck oncology, 4,35 .

12. Kyono Y., Takayama T., Kinoshita M., Kurita M., Mugiya S., Baba S., Ozono S. (2011) "Combination therapy with sorafenib and S-1 for renal cell carcinoma producing granulocyte colony-stimulating factor", International Journal of Clinical Oncology, 16(3)275-278.

13. Münstedt, K., Hackethal, A., Eskef, K., Hrgovic, I., Franke, F. E. (2010) "Prognostic relevance of granulocyte colony-stimulating factor in ovarian carcinoma." Archives of gynecology and obstetrics. 282(3)301-305.

14. Nagata, S., Tsuchiya, M., Asano, S., Kaziro, Y., Yamazaki, T., Yamamoto, O., Hirata, Y., Kubota, N., Oheda, M., Nomura, H., Ono, M. (1986) "Molecular cloning and expression of cDNA for human granulocyte colony-stimulating factor," Nature, 319 (6052) 415-418.

15. Nakamura, M., Oshika, Y., Abe, Y., Ozeki, Y., Katoh, Y., Yamazaki, H., Kijima, H., Ueyama, Y., Ogata, T., Tamaoki, N. (1997) “Gene expression of granulocyte colony-stimulating factor (G-CSF) in non-small cell lung cancer," Anticancer research, 17 (1B) 573-576.

16. Østergaard, M., Olesen, L. H., Hasle, H., Kjeldsen, E., Hokland, P. (2004) “WT1 gene expression: an excellent tool for monitoring minimal residual disease in $70 \%$ of acute myeloid leukaemia patients - results from a single-centre study," British journal of haematology, 125 (5) 590-600.

17. Sugiura, S., Makiyama, K., Nakaigawa, N., Yao, M., Kubota, Y., Oshiro, H. (2007) 
“Collecting duct carcinoma producing granulocyte-colony-stimulating factor

(G-CSF)," International journal of urology, 14(6):555-557.

18. Suzuki, A., Takahashi, T., Okuno, Y., Nakamura, K., Tashiro, H., Fukumoto, M., Konaka, Y., Imura, H. (1991) "Analysis of abnormal expression of G-CSF gene in a novel tumor cell line (KHC287) elaborating G-CSF, IL-1 and IL-6 with co-amplification of c-myc and c-ki-ras," International journal of cancer, 48 (3) 428-433.

19. Suzuki, A., Takahashi, T., Okuno, Y., Tsuyuoka, R., Fukumoto, M., Nakamura, K., Imura, H. (1992) "IL-1 production as a regulator of G-CSF and IL-6 production in CSF-producing cell lines," British journal of cancer, 65 (4) 515-518.

20. Suzuki, A., Takahashi, T., Okuno, Y., Seko, S., Fukuda, Y., Nakamura, K., Fukumoto, M., Konaka, Y., Imura, H. (1993) "Liver damage in patients with colony-stimulating factor-producing tumors," The American journal of medicine, 94(2)125-132.

21. Tahara, E. (1990) "Growth factors and oncogenes in human gastrointestinal carcinomas", Journal of cancer research and clinical oncology, 116 (2) 121-131.

22. Takahashi, T. and Kasakura, S. (2007)

"Inflammatory Markers and Cancer. XXIV

World Congress of Pathology and Laboratory
Medicine," MEDIMOND S. r. l., Bologna, (2007)77-82.

23. Terashima, T., English, D., Hogg, J. C., van Eeden, S. F. (1998) "Release of polymorphonuclear leukocytes from the bone marrow by interleukin-8," Blood, 92(3) 1062-1069.

24. Tsuyuoka, R., Takahashi, T., Sasaki, Y., Taniguchi, Y., Fukumoto, M., Suzuki, A., Nakamura, K., Kobayashi, S., Kudo, T., Nakao, K. (1994) "Colony-stimulating factor-producing tumours: production of granulocyte colony-stimulating factor and interleukin-6 is secondary to interleukin-1 production," European journal of cancer, 30A (14) 2130-2136.

25. Vassilatou. E., Fisfis. M., Morphopoulos. G., Savva. S., Voucouti. E., Stefanoudaki. K., Tzavara. I. (2006) "Papillary thyroid carcinoma producing granulocyte-macrophage colony-stimulating factor is associated with neutrophilia and eosinophilia." Hormones (Athens), 5(4)303-309.

26. Wang, Y. C., Yang. S., Tzen., C. Y., Lin, C. C., Lin, J. (2006) "Renal cell carcinoma producing granulocyte colony-stimulating factor." Journal of the formosan medical association, 105(5)414-417.

Taiichi Kodaka, Emiko Ishikawa Sakane, Hayato Maruoka, Hiroko Tsunemine, Hiroshi Akasaka, Kiminari Ito, Tetsuya Miura, Tomoo Itoh and Takayuki Takahashi (2016), Advances in Cancer Research \& Treatment, DOI: $10.5171 / 2016.711926$ 